\title{
The Development of Using Elevators in Different Buildings
}

\author{
Lamis Sayed Abdelkader ${ }^{1,2}$ \\ 1. Architectural Engineering Department, Hijawi Faculty of Engineering Technology, Yarmouk University, Jordan \\ 2. Faculty of Industrial Education, Beni-Suef University, Egypt
}

\begin{abstract}
Elevators are one of the most important elements of vertical communication used in buildings. Especially in recent times, where high and high rise buildings have become a modern architectural phenomenon and the spread of architecture has become a feature of the age. Hence, the research discusses the technique of installing elevators in buildings. A general introduction to elevators and their types will be discussed, as well as a historical overview of the beginning of the idea of the elevator and the first buildings that were used. The technique of installing the elevator inside the building explained with the images shown components elevator. Also it will mention several speeds of modern elevators used in buildings, the world's fastest elevator, ultra-rope technology and the reasons for choosing this technique in elevator components in high-rise buildings which may be used in the space elevator that will connect earth and space. As well it shows features of the wire used in the elevators of the Burj-Khalifa, the highest skyscraper in the world. Then it mentions a number of the most recent and newest elevators in the world, then research results and references.
\end{abstract}

Key words: Elevators, construction technology, hydraulic lifts, elevator installation, the fastest elevators.

\section{Introduction}

The elevator is the meaning of transportation that moves people and goods vertically from the bottom up and vice versa. The elevator is usually placed in the buildings of many floors, in order to facilitate the climb to the upper floors without hardship. Because of the laws in some countries, elevators may be legal demands in some large buildings especially if other means are impractical [1].

The mechanism of moving the elevator has varied throughout history, from the physical effort to the steam engines, the current electric motors. But the principle of work remained one, a cabin or a room strapped with a rope raised or lowered with special cases of elevators such as the one where the cabin is provided with a motor. The existing elevators, especially the electric ones, have a button panel that allows the passenger to choose the level or floor that

Corresponding author: Lamis Sayed Abdelkader, Ph.D, assistant professor, research fields: architecture design and building technology. Email: Lamisabdelkader@hotmail.com. is wanted to reach.

Lifts are often installed inside hollow columns that allow the elevator beam to move vertically (up and down). If the elevator compartment is a closed room with a door, it is sometimes with glass sides that allow the occupants to follow the outside atmosphere, whether the building's lobby, as in some hotels or markets or outside the building, especially in the buildings with glass façade [2].

Elevators have become an unavoidable necessity especially in high-rise buildings. A special type of elevator has been introduced. It is a vertical movement device, but without a cage or a cabin, but only a suitable rack that allows the stairs to be crossed. It is mainly designed to transport heavy loads and people in public places such as markets, cultural centers, factories etc. are manufactured to suit users and users.

\section{History of Elevators in Buildings}

For centuries, tall buildings (such as Greek monasteries) have been almost isolated from access through primitive elevators "without a motor". The first appearance 


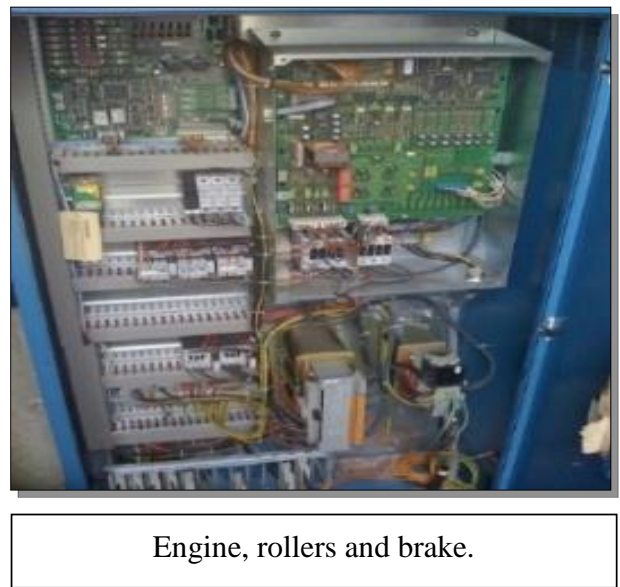

Fig. 1 Engine, rollers and brake.

of elevators was generally seen in the mines. The elevators were equipped with steam engines. The first elevators were provided by skyscrapers for the public, and at the beginning of the 19th century to the twentieth century, it was allowed to rise only on the upper floors, while the descent was limited to the stairs only [3]. The current traditional elevators are composed of an electric motor with cable and overhead load-balancing cable. Maintenance regular elevator is to re-string cable and check the safety and protection sensors of their own systems.

\section{Techniques for Installing Elevator in Buildings}

The hydraulic lifts are defined as piston systems, and the piston can move the cabin only a few floors or move a roll system through which the cable carries the cabin. The first hydraulic lifts were very slow, but the slow hydraulic system and the high cost of drilling caused the use of this system and especially the spread of electric motors.

The modern elevator engine is controlled by a vibration changer, which controls the electrical supply voltage to suit the torque required to move with acceleration or deceleration, so that it remains imperceptible to the cabin occupant (speeding the elevator increases the person's sense of weight: weight gain or reduction by about 10\%) [4].

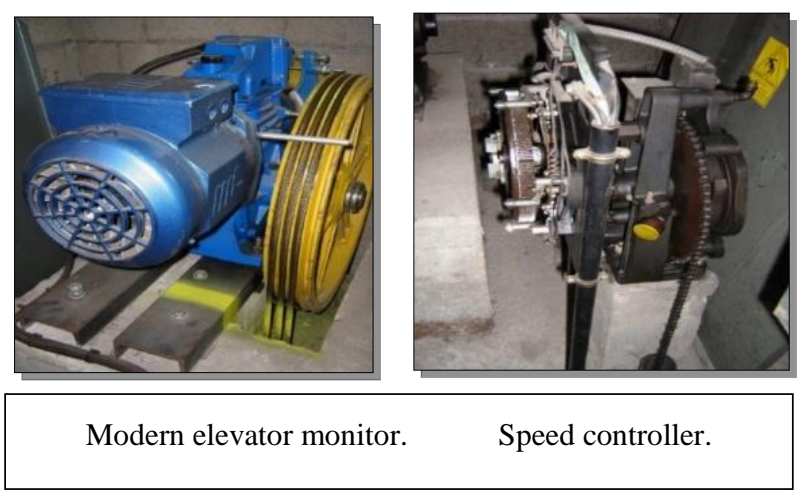

Fig. 2 Modern elevator monitor.

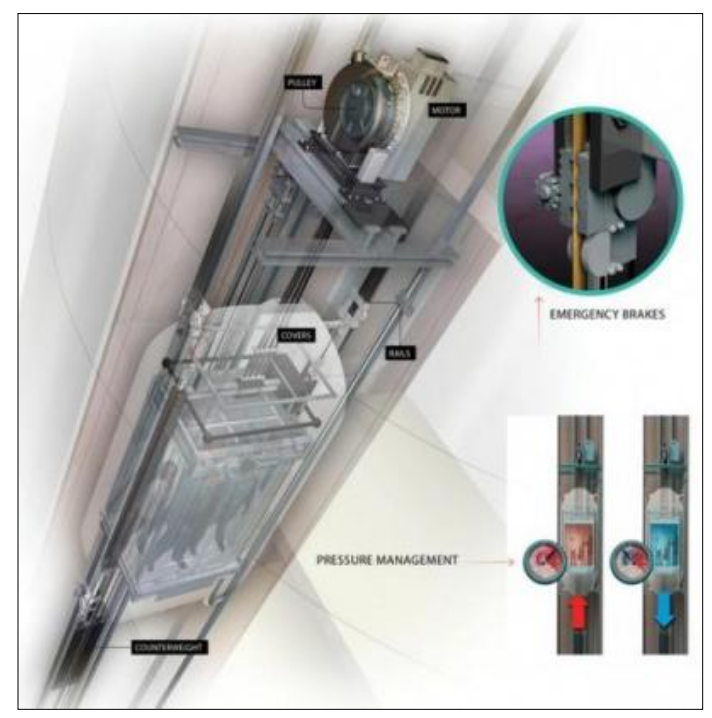

Fig. 3 Elevator Isometric.

\section{The Main Components of the Elevator}

The elevator is made up of a compartment or a vertical cage in general. It supports the cabin with a parallel structure that allows direction and support of the cabin. The direction is guided by various elements, two directions along the cabin path and two on either side of the cabin. The movement of the cabin, lubricated regularly to reduce friction and noise, can in some cases be replaced by small wheels (diameter from $80 \mathrm{~mm}$ to $200 \mathrm{~mm}$ ) as in high-speed compartments or heavy loads.

\section{The Speed of Elevators in Different Buildings Height}

For elevators in classic apartment buildings, stores and parking are typical speeds of $0.6 \mathrm{~m} / \mathrm{s}$ to $2.5 \mathrm{~m} / \mathrm{s}$, 
about 2 to $9 \mathrm{~km} / \mathrm{h}$. For speed elevators in towers or skyscrapers: The maximum speed of the elevator reaches 17 or 18 meters per second $60 \mathrm{~km} / \mathrm{h}$, for longer elevator towers such as Taipei 101 in Taipei or Burj Khalifa in Dubai, beyond $11 \mathrm{~m} / \mathrm{s}$ there are health risks [5].

The acceleration required to reach the speed of modern elevators is often fixed and measured at $\pm 1 \mathrm{~m}$ $\mathrm{s}$ in square meters $\left(1 \mathrm{~m} / \mathrm{s}^{2}\right)$ or $\pm 0.1 \mathrm{G}$ (gravity), but in many old lifts it is disorganized and often large.

\section{The Fastest Elevator in the World}

Heachi is a Chinese company planning to build the world's fastest elevator skyscraper in China, provides one of the fastest elevators in the world, to be built in CTF building which is currently under construction in Guangzhou, South China and will consist of 111 floors above ground and contain numbers of apartments and a hotel in addition to administrative offices [6].

\section{Technology of Ultra-Rope}

It is a modern technology used to lift heavy weights, allowing elevators to reach a distance of up to twice the distance from other systems, using cables of light carbon fiber instead of heavy steel cables, with the construction of skyscrapers in all regions of the world, the challenges faced by companies are elevators, as the elevators are restricted by the weight of the steel wires required for lifting, in addition to other factors such as air pressure and the cost of electrical power for elevators. This technique has been developed and used in high-rise buildings for the following reasons:

- Lower cost: less than $85 \%$ of the cost of power needed to operate this type of elevator, and the cost of maintenance is lower; because the carbon fiber lasts longer than double the length of steel wire.

- Climate conditions such as pressure and temperature: The speed of elevators is 17 meters per second, while the usual speed of pressure changes on our bodies is only 10 meters per second.
- Weight loss: This technology reduces the weight of elevator wires by more than $90 \%$ through carbon fiber instead of steel. The weight of steel wire at 400 meters is $18.650 \mathrm{~kg}$, but using carbon fiber, it will weigh only $1.170 \mathrm{~kg}$. The light weight of the wires helps to restrain the elevator vehicle more easily when any defect occurs.

- Strength and hardness: Carbon wire is characterized by the difficulty of breaking when pulled to its ends, similar in strength to diamonds, and the strength of the hardness is 180 times the strength of the steel.

The same steel wire was used in the installation of the Khalifa Tower elevators ( 828 meters high) in Dubai, after they were coated with polyurethane.

The technology allows elevators to reach the highest point at a distance of one kilometer at a time. The technology is being modified and controlled at a research center in the Finnish city of Titre, in an unused mine in the form of a $350 \mathrm{~m}$ deep underground tower [7].

\section{Characteristics of the Wires Used in the Elevators of the Tower of Khalifa as the Highest Skyscraper in the World}

Flexibility: As the foam density of the polyurethane is low, it gives the ease of change, adaptation and support for the steel material.

Cost: Less than $50 \%$ of the cost of energy needed to operate this type of elevator, and it has reduced the weight of wires.

High corrosion resistance: It insulates wires from moisture, heat, and corrosion due to intensive use.

\section{Space Elevator}

It is worth noting that these carbon fibers will be used to build space elevators between the planet and space stations, and thus access to space and return safely to Earth. It will also be a cost-effective alternative to missiles. The cost of a missile is $\$ 25,000$ per kilogram, while the value is $\$ 220$. The company, 


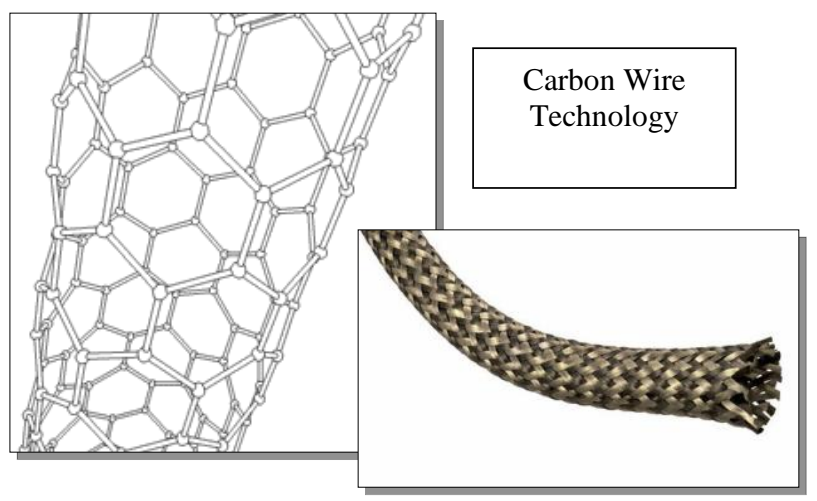

Fig. 4 Carbon wire technology.

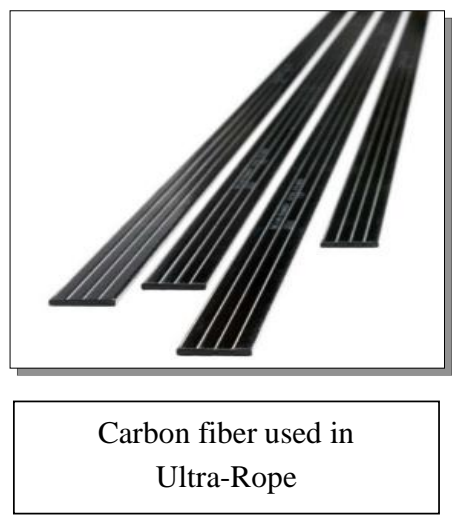

Fig. 5 Carbon fiber used in utra-rope.

called Thoth Technology, obtained the US patent to build a "space elevator" that would be 20 times longer than Burj Khalifa in Dubai. The height of the space elevator will be higher than the Armstrong Limit. The company believes that the tower will be of great importance in the launch of space ships from the upper atmosphere of the Earth, due to low fuel consumption when the launch of vehicles from the platform is located at the top of the tower, and researchers say it can ease the cost of space flight by about a third [8].

\section{Examples of the Most Popular Lifts in the World}

The Aqua-Dom basin in Berlin, the world's largest cylindrical aquarium, is 25 meters long and has a glass elevator inside so that the tourist can see the living things in this giant aquarium.

Sky Tower is located in Auckland, New Zealand, a 328-meter-tall observation tower, making it the tallest

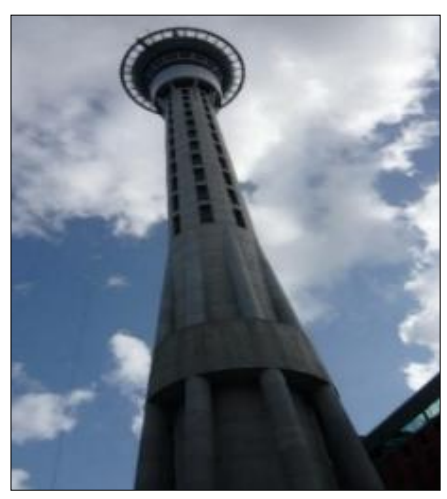

Fig. 6 Sky Tower in Auckland, New Zealand.

tower in the Southern Hemisphere. The observation point, up to 185 meters high, can be reached in just 40 seconds through its glass-faced lifts and floor.

The Escrada elevator connects Brazil, between the old and the new part of Salvador, and is used by more than 30,000 people a day. The elevator reaches 72 meters in 38 seconds [9].

The Hammerschwand elevator in Switzerland is the highest outdoor lift in Europe, connecting the rock track with the Hammerschwand observation post over the Bergnostk Mountain overlooking Lake Lucerne. The elevator rises 153 meters to the top of Hammerschwand in less than minutes, and is considered a major tourist attraction.

To reach the top of the Eiffel Tower in France, visitors first have to ride an elevator to the first floor, which is not a traditional vertical lift. Starting from the second floor, visitors head to the top of the tower via a traditional vertical elevator [10].

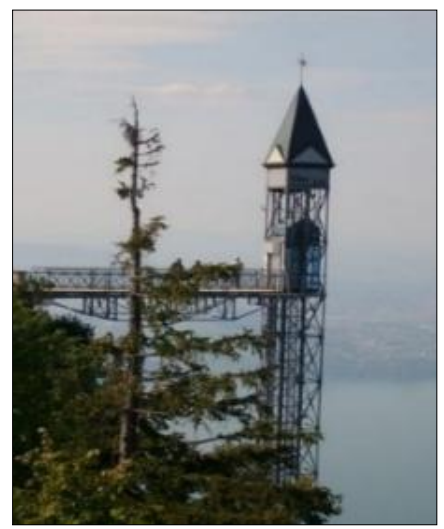

Fig. 7 The Hammerschwand elevator in Switzerland is the highest outdoor lift in Europe. 


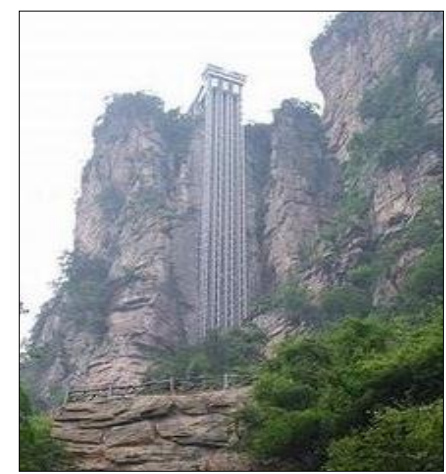

Fig. 8 The Bailong elevator built in China a 330 meter glass elevator.

The Bailong elevator was built in China on a huge cliff in Wulingyuan, a 330 meter glass elevator, arguably the tallest and heaviest outdoor lift in the world. It was built in 1999 and opened to the public in 2002.

\section{Results}

Elevators have emerged as a result of the prolongation of the structure that has become a feature of our modern era.

There is an urgent need for the development of elevators and cables as a result of the fact that it is possible to build buildings a kilometer above the ground.

The innovation of nanotechnology has contributed significantly to the development of hard carbon nanotubes that may be used to build a future space elevator.

The idea of building a space elevator has achieved the constant connection between Earth and space and this old idea may become a reality in the near future.

Elevator is one of the most important elements of vertical communication located in tall buildings.

Elevator components and installation techniques of the most important structural and architectural techniques, are very important to study as well as the development and accuracy.

The idea of a space elevator has created the imagination of modern architects to wonder whether it is possible someday to achieve the same idea in the interior of the earth to be discovered or to undertake trips to the underground, for example, to reach the depths of the ocean, or reach the top of a giant mountain base or to reach depths deeper than the depths of the mine.

\section{References}

[1] Mohamed Shawki, A. L. 2015. 1th Century Architectural Trends, 1st ed. Egypt: Mansoura Press.

[2] Mohammed Al, B. 2001. Art in the Twentieth Century. Egypt: Egyptian General Book Authority.

[3] Charles, J. 1997. Architecture of the Jumping Universe. London: Academy Editions.

[4] James, S. 1997. Architecture Today. London: Phaidon Press.

[5] French magazine Lebl, No. 42, January 2001, French Ministry of Foreign Affairs.

[6] Haidar, F. A. 2006. The Modern Encyclopedia of Building Construction Technology, The Basics of Building Construction, Part One, 9th ed. Alexandria: Al-Ma'aref Establishment.

[7] Raafat, A. 2007. Environmental Course-Building of the Future, Triangle of Architectural Creativity, Intellectual Creativity Courses, Cairo. 1st ed.

[8] Leydecker, S. 2010. Nano Materials in Architecture, Interior Architecture and Design. Weimar, Berlin (translation): Julian Reisenberger.

[9] National Museums of Scottland (NMS). 2002. Exhibition for All: A Practical Guide to Designing Inclusive Exhibitions. NMS Publishing Ltd. http://swfed.org.uk/images/resources/Users__Visitors/acc ess/EXhibitions_for_all_NMScotland.pdf.

[10] National Assembly of State Arts Agencies (NASAA). 2003. Design for Accessibility: A Cultural Administrator's Handbook. NEA, NEH, and the Kennedy Center, USA. https://www.arts.gov/sites/default/files/Design-for-Accessi bility.pdf. 